Article

\title{
Designing for Circularity-Addressing Product Design, Consumption Practices and Resource Flows in Domestic Kitchens
}

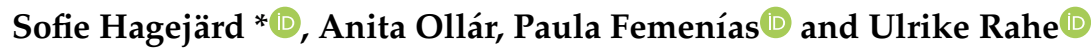 \\ Department of Architecture and Civil Engineering, Chalmers University of Technology, SE-412 96 Gothenburg, \\ Sweden; ollar@chalmers.se (A.O.); paula.femenias@chalmers.se (P.F.); ulrike.rahe@chalmers.se (U.R.) \\ * Correspondence: sofie.hagejard@chalmers.se
}

Received: 21 December 2019; Accepted: 28 January 2020; Published: 30 January 2020

check for updates

\begin{abstract}
Both the daily use and renewal of kitchens significantly contribute to the overall environmental impact of domestic buildings. To identify design implications related to circular consumption in domestic kitchens, 20 household interviews and one focus group session were performed, investigating how kitchens are used and transformed to meet households' wants and needs. This study determined that daily kitchen resource use is greatly affected by kitchen design and that typical kitchen design generally does not promote sustainable resource use. Key factors that support minimization of resource use in the kitchen are the availability and planning of storage and workspaces. Furthermore, kitchens should be equipped with functions that enable households to use energy and water efficiently. Regarding kitchen renewal, various motivations that may initiate kitchen renovations can be summarised as follows: (1) Functional demands and changing needs, (2) aesthetic demands and changing trends, (3) obsolescence due to wear, and (4) linkage to another home renovation. This article concludes that a combination of design strategies is needed to reach a higher level of kitchen circularity. Moreover, these design strategies must be accompanied by circular business models and efforts to increase awareness of the environmental impact related to activities in and involving the kitchen.
\end{abstract}

Keywords: circular economy; circular product design; sustainable consumption; practice theory; user-centred design; domestic kitchens; product lifetime extension

\section{Introduction}

Kitchens have become increasingly multifunctional living spaces and a frequent target for renewal [1,2]. Appliances and cabinets in the kitchen have been found to represent major contributors to the overall environmental impact of domestic buildings [3] and the climate impact related to apartment renovations [4]. Each year, 10 million tonnes of furniture are discarded in the European Union, of which kitchen furniture represents approximately one-fourth [5]. Only $10 \%$ of this discarded furniture is recycled, whereas the majority ends up in a landfill or is incinerated [6]. Furthermore, a growing number of appliances per household [1] in combination with declining appliance lifespans [7] has led to a steady increase in home appliance waste in Europe, amounting to five million tonnes in 2016 [8].

Initiating a circular economy has been proposed as a strategy to improve sustainability and wellbeing at minimal material, energy, and environmental costs, but the 'circular transition' remains at an early stage [9]. A wide range of barriers obstruct the move forward, for instance, increasingly complex product design and functionality [10], low material quality, high costs of repair and refurbishment, and weak demand for second-hand products [5]. 
The Ellen MacArthur Foundation defines a circular economy as a system that is 'restorative and regenerative by design and aims to keep products, components, and materials at their highest utility and value at all times' [11]. A crucial question in the development of more circular products and business models is whether such circularity actually, in the end, provides solutions with lower environmental impact [12]. According to Wastling et al., a majority of the present literature on circular design has focused on technical aspects of products rather than on how to design them to fit with people's needs, desires, and behavioral patterns [13]. End-users play a critical role in a circular economy because their decisions determine how products are obtained, the extent to which products are utilized, as well as what happens with products once their users no longer need them [14].

In addition to having an effect on the circular use of products, from furniture to appliances and other equipment, present in domestic kitchens, households' decisions and practices in everyday life significantly influence the energy consumption and environmental impact connected to kitchen use. According to Elias et al., user-related losses constitute a significant share of the energy use by domestic products. Such losses are also likely to increase in proportion as technological development of appliances continues to reduce intrinsic energy losses from, for instance, poor insulation or excess heat [15]. Hager and Morawicki highlighted the need to address user behavior and practices to reduce the environmental impact of cooking [16], and Hobman et al. identified the category of household kitchen practices as one of the most promising areas for behavior change in the home [17].

There is currently a lack of research regarding opportunities to apply design strategies and business models drawn from the circular economy to extend the useful life of kitchens and minimize the environmental impact of kitchen use. However, in order to enable the transition of domestic kitchens to the circular economy framework, it is important to first understand how kitchens are used in everyday life and also why kitchens tend to be replaced before the end of their functional lifespan. The aim of this article is thus threefold:

1. to explore households' everyday resource use in the kitchen,

2. to explore typical motivations for renovating domestic kitchens,

3. to suggest design strategies that can enable circular consumption in and around domestic kitchens with respect to both the products used in the kitchen and the resource flows in the daily use of the kitchen.

The theoretical framework for the analysis is based on literature on circular design strategies and social practice theory.

The article is structured as follows: Section 2 provides background information covering the research context, the terminology used in the paper, and the theoretical framework. Section 3 describes the research approach and methods used in the study, followed by a presentation of the findings in Section 4 . The findings are subdivided into resource consumption in the daily use of kitchens, kitchen renewal, and barriers to kitchen circularity. A discussion centered on the design approaches that can enable circular consumption of kitchens and in the daily use of kitchens is presented in Section 5 . Finally, Section 6 summarises the conclusions of the paper.

\section{Background}

\subsection{Research Context}

The study reported in this paper was conducted within the framework of the Circular Kitchen project (CIK) as part of the EIT Climate-KIC. In collaboration with international academic and industry partners (housing developers, kitchen manufacturers and appliance producers), the research team aims to develop new types of kitchen furniture and appliances, accompanied by a business model based on circular economy principles. To successfully reach this objective, it is critical to understand the end-users' needs and demands. Therefore, research activities, such as a focus group session and interviews, were designed to collect insight into end-user perspectives regarding kitchens. 


\subsection{Terminology}

To clarify the meanings of the terms used in the study, Table 1 provides a list of terms and their explanations.

Table 1. Terminology employed in this study.

\begin{tabular}{|c|c|}
\hline Term & Explanation \\
\hline kitchen & $\begin{array}{l}\text { In this paper, the term 'kitchen' is used in a holistic sense. } \\
\text { The meaning incorporates the in-built and flexible furniture, the appliances, } \\
\text { the room itself, and connected infrastructures. }\end{array}$ \\
\hline kitchen renovation & $\begin{array}{l}\text { Kitchen renovations vary widely in scale from minor adjustments to complete } \\
\text { renovations. In the following, kitchen renovations must be understood as any type } \\
\text { of adaptation of the kitchen furniture, the appliances, or the space of the kitchen. } \\
\text { The in-built elements of the kitchen are referred to as kitchen furniture. }\end{array}$ \\
\hline kitchen furniture & $\begin{array}{l}\text { These include fixed cabinets, furniture doors, countertops, drawers, shelves, and } \\
\text { the sink. However, kitchen appliances are excluded from this terminology. } \\
\text { Larger, more or less fixed electronic kitchen devices are included in the term }\end{array}$ \\
\hline kitchen appliances & $\begin{array}{l}\text { kitchen appliances. More specifically, the fridge, freezer, stove, oven, ventilation } \\
\text { hood, and dishwasher are classified as kitchen appliances. }\end{array}$ \\
\hline rental apartments & $\begin{array}{l}\text { Apartments that are leased temporarily from a landlord to a tenant are rental } \\
\text { apartments. The contract might be first-hand (rental directly from the landlord) or } \\
\text { second-hand (rental through the first-hand tenant). }\end{array}$ \\
\hline condominiums & $\begin{array}{l}\text { In Sweden, a special type of home ownership (bostadsrätt) is recognized. } \\
\text { In this case, the residents collectively own the apartment building, and all are } \\
\text { members of a housing association that manages the buildings belonging to it. } \\
\text { This type of apartment is referred to as a condominium in this paper. }\end{array}$ \\
\hline housing association & $\begin{array}{l}\text { In Sweden, a housing association (HA) is an economic organization owned by the } \\
\text { residents of the buildings belonging to the HA. Each resident owns an equal share } \\
\text { in the HA. This means that the residents do not directly own their apartments but } \\
\text { collectively own the building and its apartments within the HA. The members of the } \\
\text { HA form a management board that is responsible for managing the matters of the } \\
\text { HA. The board usually has to approve all major renovation plans in the apartment. }\end{array}$ \\
\hline kitchen resource use & $\begin{array}{l}\text { Kitchen resource use concerns the resources used during the whole kitchen } \\
\text { lifecycle, including resources used in the production of kitchen furniture, } \\
\text { appliances, and other products in the kitchen, during the kitchen use phase(s), } \\
\text { and at the kitchen's end of life. }\end{array}$ \\
\hline end-users & $\begin{array}{l}\text { In this paper, the term 'end-users' refers to households, regardless of dwelling type, } \\
\text { and how they use the kitchen in their everyday life at home. }\end{array}$ \\
\hline
\end{tabular}

\subsection{Circular Design Strategies}

Various frameworks for circular design strategies have been suggested by a growing number of researchers in recent years. This section presents approaches that have been purposefully selected for the analysis of the data. Moreno et al. undertook a literature review of various Design for Sustainability (DfX) approaches and presented a circular design framework that included the following design strategies:

1. design for circular supplies,

2. design for resource conservation,

3. design for multiple cycles,

4. design for long life use of products,

5. design for systems change.

They contended that by applying systems thinking, 'designers have the potential to influence consumer perceptions and consumption patterns to help industry and society to not only move away from careless resource depletion but transition towards an abundant, innovative and prosperous future, enabling a true adoption of circular design' [18]. 
Bocken et al. introduced the terminology of slowing, closing, and narrowing resource loops and proposed product design strategies corresponding to the first two categories. The category of slowing loops is divided into the subcategories of designing long-life products and design for product-life extension. The first includes design for attachment and trust, and design for reliability and durability. The second includes design for ease of maintenance and repair, upgradeability and adaptability, standardization and compatibility, and dis- and reassembly. Suggested design strategies to close loops are design for a technological cycle, biological cycle, and dis- and reassembly [19]. den Hollander et al. introduced the concept of design for product integrity, which involves deploying strategies to resist, postpone, and reverse product obsolescence. The first category, resisting obsolescence, entails the strategies of designing for physical as well as emotional durability. The second category, postponing obsolescence, entails the strategies of design for maintenance and upgrading. Finally, the category of reversing obsolescence involves the strategies of design for recontextualizing, repair, refurbishment, and remanufacture [20].

\subsection{Social Practice Theory}

Social practice theory has been applied in various studies to understand residential energy use, e.g., [21-23]. It has also been used for understanding everyday kitchen life [24], kitchen transformation and renewal [25], and to study the use of specific appliances within the kitchen [26,27].

A practice can be described as 'a routinized type of behavior which consists of several elements, interconnected to one other: Forms of bodily activities, forms of mental activities, "things" and their use, a background knowledge in the form of understanding, know-how, states of emotion and motivational knowledge' [28]. Shove et al. proposed a slightly simplified and commonly used categorization of elements into three groups: Materials, competences, and meanings [29]. These groupings are sometimes rephrased as stuff, skills, and images [30]. According to Shove et al., materials are objects, infrastructures, tools, hardware, and the body itself. Competences refer to multiple forms of understanding and practical knowledge, including know-how, learned skills, and shared understandings of what is good or appropriate. Meanings are 'the social and symbolic significance of participation at any one moment' [29] (p. 24). Furthermore, according to Shove et al., 'practices change when new elements are introduced or when existing elements are combined in new ways' [29] (p. 87).

Practices can further be categorized as practice-as-entity or practice-as-performance. Practice-as-entity captures how elements are linked and how actions are supposed to be performed. In comparison to practices-as-performances, practices-as-entities persist over time but are dependent on repeated performances [30]. Practice-as-performance is more dependent on the specific situation and may, therefore, vary slightly from time to time [30].

\section{Research Approach and Methods}

This paper reports on the empirical data that were gathered during a focus group meeting in a selected resident-owned housing association (HA) and semi-structured interviews with randomly selected households of various residence tenures. The questions asked during the sessions aimed to elicit user behavior patterns, renovation strategies, resource use, and visions for future kitchens. The discussions were audio-recorded, transcribed, and thematically analyzed. Pseudonyms were applied to respondents to prevent any specific comment or information being connected to any individual in the study. The audio recordings and transcriptions have been stored in a secure manner to protect the personal data of the interviewees. Each participant signed a consent form specifically tailored to this study's explicit proceedings. The data collection was performed during a one-year period from November 2018 to November 2019. All participants in the study were given a cinema ticket in appreciation for their participation. 


\subsection{Focus Group}

According to Flick, focus groups are an excellent means of collecting a wide range of inputs because the individuals in the group challenge, confirm, and build upon each other's statements [31]. The authors used the focus group setting for one specific activity in the CIK project. This activity involved a particular HA, which was selected as they showed high interest in the research topic. Furthermore, this specific HA and the manufacturer of the kitchen furniture initially installed in the apartments were both partners in the CIK project.

The focus group meeting with the HA was the second in a series of research activities. It followed a survey-like approach (a 'kitchen diary') which was designed to retrieve information about the households and their kitchens (e.g., setup, layout, use, appliances) and easing the residents into the topic while preparing for the next step with a sign-up invitation for focus groups. The survey was sent out to 90 households living within the HA. However, unfortunately, only 10 kitchen diaries were sent back. Due to the small number of responses, the data were deemed to be non-representative. Consequently, the authors will not discuss it in this publication.

Six adults from the HA attended the focus group meeting that was held in February 2019. As Table 2 shows, mostly elderly people took part in the discussions. Even though this was the only focus group activity in the study, it proved to be a valuable event because the researchers gained valuable insight into kitchen-related topics through the opinions and thoughts of one specific age group (elderly adult/65+). Although, due to a lack of information regarding household demographics of the HA in general, it was not possible to determine if the focus group participants were representative of the entire HA population or not.

Table 2. Summary of the focus group participants' demographic information.

\begin{tabular}{ccccccccc}
\hline Case & Gender & Age & Adults & Children & $\begin{array}{c}\text { Dwelling } \\
\text { Type }\end{array}$ & $\begin{array}{c}\text { Dwelling } \\
\text { Size } \mathbf{( m}^{\mathbf{2}} \mathbf{n}\end{array}$ & $\begin{array}{c}\text { Number of } \\
\text { Rooms } \mathbf{1}\end{array}$ & Nationality \\
\hline F-1 & Woman & $75-84$ & 1 & 0 & Condominium & 66 & 2 & Swedish \\
F-2 & Woman & $75-84$ & 1 & 0 & Condominium & 62 & 2 & Swedish \\
F-3 & Woman & $65-74$ & 1 & 0 & Condominium & 79 & 3 & Swedish \\
F-4 & Woman & $65-74$ & 1 & 0 & Condominium & 71.3 & 3 & Swedish \\
F-5 & Man & $65-74$ & 2 & 0 & Condominium & 107 & 4 & Swedish \\
F-6 & Woman & $35-44$ & 2 & 2 & Condominium & - & - & Swedish \\
\hline
\end{tabular}

The session was guided by a list of semi-structured questions prepared by the research team. These questions focused on activities, resource use, completed or desired changes in the kitchen, and visions for future kitchens.

The focus group session was held in a common activity room of the HA. Three researchers organized the session, and during the session, the first author assumed the role of moderator and the second author and a third researcher shared the tasks of taking notes and pictures as well as posing additional questions as needed. The focus group was audio-recorded with permission from the participants. Light food and snacks were available during the entire session, which lasted for two and a half hours with a break in the middle. The language used in the focus group was Swedish.

\subsection{Interviews}

The participants were recruited through various channels: 1) A social media advertisement, 2) the newsletter of a housing developer, and 3) personal contacts and snowballing. Through these recruitment methods, 20 interviewees were identified. The selection criteria were loosely defined because the aim was to reach a wide range of ages, household compositions, and dwelling types. Our preference was for subjects who had completed some type of renovation in the kitchen, but this 
was not a criterion. Additionally, it was desirable to include a mix of different cultural backgrounds, but this was also not a criterion.

As Table 3 indicates, the interview study participants comprised residents of seven rental apartments, six owner-occupied condominiums, one terraced house, and six villas. The participants represented a broad range of ages, household compositions, and dwelling types as well as some variation in cultural backgrounds, as indicated by the last column. This composition yielded rich insights into a wide scope of end-users' demands for kitchens.

A limitation of the study is that information regarding income levels was only collected at the individual level for the particular interviewees rather than at the total household level. Therefore, this information is not included in the table because it cannot be used to draw conclusions about the households' purchasing power.

Table 3. Summary of the interview participants' demographic information.

\begin{tabular}{|c|c|c|c|c|c|c|c|c|}
\hline Case & Gender & Age & Adults & Children & $\begin{array}{c}\text { Dwelling } \\
\text { Type }\end{array}$ & $\begin{array}{l}\text { Dwelling } \\
\text { Size }\left(\mathrm{m}^{2}\right)\end{array}$ & $\begin{array}{c}\text { Number of } \\
\text { Rooms } 1\end{array}$ & $\begin{array}{c}\text { Languages } \\
\text { Spoken at } \\
\text { Home }^{2}\end{array}$ \\
\hline $\mathrm{I}-1$ & Woman & $35-44$ & 2 & 1 & Condominium & 83 & 3 & - \\
\hline $\mathrm{I}-2$ & Woman & $35-44$ & 2 & 3 & Villa & 133 & 5 & - \\
\hline $\mathrm{I}-3$ & $\begin{array}{c}\text { Man } \\
\text { Woman }\end{array}$ & $\begin{array}{c}25-34 \\
-\end{array}$ & 2 & 2 & $\begin{array}{l}\text { Terraced } \\
\text { house }\end{array}$ & 106 & 4 & - \\
\hline $\mathrm{I}-4$ & Man & $25-34$ & 2 & 0 & Condominium & 74 & 3 & - \\
\hline $\mathrm{I}-5$ & Woman & $25-34$ & 2 & 1 & $\begin{array}{c}\text { Rental } \\
\text { apartment }\end{array}$ & 63 & 2 & $\begin{array}{l}\text { French, } \\
\text { English }\end{array}$ \\
\hline I-6 & $\begin{array}{l}\text { Woman } \\
\text { Man }\end{array}$ & $\begin{array}{l}25-34 \\
25-34\end{array}$ & 2 & 0 & Condominium & 64.7 & 3 & - \\
\hline $\mathrm{I}-7$ & Woman & $35-44$ & 2 & 2 & Villa & 120 & 5 & - \\
\hline $\mathrm{I}-8$ & Woman & $45-54$ & 2 & 2 & Condominium & 109 & 5 & Somali \\
\hline I-9 & Woman & $45-54$ & 2 & 3 & Villa & 240 & 9 & - \\
\hline $\mathrm{I}-10$ & Man & $35-44$ & 2 & 3 & Villa & 170 & 7 & German \\
\hline $\mathrm{I}-11$ & Woman & $55-64$ & 2 & 0 & Condominium & 46.5 & 2 & - \\
\hline $\mathrm{I}-12$ & $\begin{array}{l}\text { Woman } \\
\text { Man }\end{array}$ & $\begin{array}{l}75-84 \\
75-84\end{array}$ & 2 & 0 & Condominium & 89 & 3 & - \\
\hline $\mathrm{I}-13$ & $\begin{array}{l}\text { Woman } \\
\text { Man }\end{array}$ & $\begin{array}{l}45-54 \\
55-64\end{array}$ & 2 & 0 & Villa & 180 & 8 & German \\
\hline $\mathrm{I}-14$ & Man & $55-64$ & 3 & 0 & Villa & $\sim 90$ & 4 & - \\
\hline $\mathrm{I}-15$ & Man & $25-34$ & 1 & 0 & $\begin{array}{c}\text { Rental } \\
\text { apartment }\end{array}$ & 72 & 3 & Farsi \\
\hline $\mathrm{I}-16$ & Woman & $55-64$ & 1 & 0 & $\begin{array}{c}\text { Rental } \\
\text { apartment }\end{array}$ & 51 & 2 & - \\
\hline $\mathrm{I}-17$ & Man & $25-34$ & 2 & 1 & $\begin{array}{c}\text { Rental } \\
\text { apartment }\end{array}$ & 75 & 3 & - \\
\hline $\mathrm{I}-18$ & Woman & $35-44$ & 3 & 0 & $\begin{array}{c}\text { Rental } \\
\text { apartment }\end{array}$ & 98 & 4 & Bosnian \\
\hline $\mathrm{I}-19$ & $\begin{array}{c}\text { Woman } \\
\text { Man }\end{array}$ & $\begin{array}{c}45-54 \\
-\end{array}$ & 2 & 1 & $\begin{array}{c}\text { Rental } \\
\text { apartment }\end{array}$ & 90 & 3 & - \\
\hline $\mathrm{I}-20$ & $\begin{array}{c}\text { Man } \\
\text { Woman }\end{array}$ & $\begin{array}{l}55-64 \\
45-54\end{array}$ & 2 & 0 & $\begin{array}{c}\text { Rental } \\
\text { apartment }\end{array}$ & 45 & 1.5 & English \\
\hline
\end{tabular}


Semi-structured interviews were conducted following an interview guide. Subsequently, the interviewees completed a quick survey regarding demographic data. The interview questions were grouped into five themes: 1) General issues related to the kitchen (e.g., 'What do you think about your kitchen in general?'), 2) cooking habits and other activities performed in the kitchen (e.g., 'Could you please describe the cooking habits of your household?'), 3) resource use in the kitchen (e.g., 'Do you find that your kitchen in any way supports or hinders the efficient use of resources (such as water, energy, food, and packaging materials)?'), 4) completed or desired changes in the kitchen (e.g., 'Have you changed or remodeled anything in the kitchen since you moved in?'), and 5) visions for future kitchens (e.g., 'What would you like your kitchen to look like 10 years from now?'). The interview guide provided an outline, but the order in which the questions were asked and which particular ones were included depended on the participants and how the conversations developed during the interviews.

The interviews were mainly held in the homes of the participants, with two exceptions where the participants preferred to have the interview via phone or Skype instead. All interviews were conducted in Swedish.

\subsection{Analysis of Collected Data}

The transcription process followed a protocol prepared by the research team. This protocol ensured consistency between the different transcribers and the final transcriptions. The protocol required moderate accuracy, meaning that the transcribers had to write exactly what was said and by whom but could omit unintelligible utterances and nonverbal nuances. This resulted in semi-open transcripts [32]. The researchers aimed to capture all kinds of input from the participants through recording extensive transcripts but keeping a focus on previously defined research questions.

The transcribed material was analyzed using the software NVivo 12. The preliminary coding structure was developed by the first author. Inspired by Gioia et al. [33], the analysis was performed in steps starting with a first-order analysis using informant-centric terms and codes with little attempt to categorize material, followed by a second-order analysis that entailed a search for emerging theoretical themes. These themes were in turn divided into eight aggregate dimensions. The first author coded the focus group and half of the interviews, and the other half was coded by the second author. New nodes were added in case any identified relevant information did not fit the original list of nodes. After the coding was completed, the two first authors reviewed the results. Some similar nodes were merged, and the coding was partly iterated to make sure that no relevant information was excluded. Illustrative quotes were picked out and translated into English by the first author.

As a result of the coding, the eight main aggregate dimensions together contained more than 300 base-level nodes. Due to the complexity of the coding structure, it cannot be described in detail here. However, the eight aggregate dimensions were named 'kitchen use', 'resource use', 'kitchen design, layout, and space', 'appliances', 'changes and renewal', 'choices before buying the flat', 'kitchen circularity', and 'future kitchens'. After the coding was finalized, the material was revisited to extract ascendant phenomena that were crossover themes among the identified aggregate dimensions. Subsequently, these themes constituted the final structure of the presentation of the empirical material in this paper.

Material concerning the lifetime and circularity of kitchens was compared to the circular design strategies presented earlier in Section 2.3. This analysis focused on identifying design strategies that could solve or mitigate problems highlighted by the participants, as well as comparing the existing frameworks with the participants' own ideas to identify possible corresponding strategies or eventual gaps. Similarly, material concerning resource use in the kitchen was analyzed from a social practice theory perspective, as described in Section 2.4. 


\section{Findings}

In this section, the findings from the previously described research methods are presented in three main subsections that cover resource use in the daily use of kitchens, kitchen renewal, and barriers to kitchen circularity.

\subsection{Resource Consumption in the Daily Use of Kitchens}

Resource consumption in the daily use of kitchens was a discussion topic in both the focus group and interviews. Activities that the households perceived as especially resource-intensive were, for instance, using the oven, washing the dishes, heating water, leaving devices and lights on when not in use, and food suppliers' packaging of groceries. Various barriers to and strategies for trying to save resources in everyday kitchen use appeared in the discussions concerning energy and water, food, and packaging waste.

\subsubsection{Energy and Water}

It became clear that energy savings are seldom prioritized when using the kitchen to cook. One interviewee declared, "I couldn't care less whether I use the oven or the stove-there I have no problem wasting resources. If I want to heat a pizza, I'll use the oven even though it's just one pizza" (I-10). Another interviewee explained as follows:

“No, it's not like it's my highest priority when I'm cooking to save energy-it is that I'm hungry [laughing]. Then I want energy! ( ... ) It's not like I'm thinking while I use the kitchen that 'now I should time it so that I turn on the oven at exactly the right minute to make it fit', I don't." (I-4)

The focus group participants explained how they were unaware of the amount of energy and water that they used in the kitchen. In their case, as HA residents, water is commonly charged for the whole building, and therefore, there is no incentive to reduce individual water consumption. They also discussed how energy is too cheap and opined that people might feel more motivated to save energy if it were more expensive. One of the focus group participants had, at a previous residence, an energy meter installed in a visible location that she passed frequently in her home. She described it as nagging and would have preferred to have it located somewhere covered so that she could choose, on her own accord, when she wanted to look at it. After discussions in the focus group, the participants seemed to agree that information regarding total household energy consumption is too general and that it would be more useful to have information regarding specific consumption by each appliance.

One interviewee pointed out that she simply did not know how she could minimize her water use further. Some participants talked about experiences in other contexts where the availability of drinking water is more limited, for instance, living on a boat, in a caravan, or a cottage without electricity and running water. In these settings, the participants explained that they felt more aware of their water consumption. Two participants believed this awareness had somewhat spilled over to their normal lives where drinking water is essentially always available. One of them explained how a mindset changes between settings:

"The sick thing is that we have that mindset there, but here, when you're home, it's just like you forget it. Why wouldn't we be able to pour water into a bowl and rinse all the vegetables in it like we do there? But somehow it's not in that environment so you don't really think like that." (I-2)

It seemed common to remember to turn off the tap when not in use. However, something that several interviewees and focus group participants described as a contributing factor to using more water than necessary in the kitchen was the slow change from warm to cold and cold to warm water. As a strategy for always having cold drinking water available without having to wait for the tap water 
temperature to shift, two focus group participants explained that they fill bottles of tap water and keep them in the fridge. Another strategy for minimizing water consumption mentioned by two participants was to reuse water left over in a kettle for watering plants.

Using the dishwasher was described as a more resource-efficient option than washing dishes by hand. One interviewee living in a newly built rental apartment explained that "environmentally, I reacted (negatively) when I moved here that there was, for instance, no dishwasher installed. You use up quite a lot of water here, so I think that's a drawback, so that's something I will install myself eventually" (I-16). Three interviewees pointed out that they always make sure to run a full dishwasher, a strategy that concerns both water and energy efficiency. Overall, the participants seemed to appreciate energy-efficient appliances that consume less energy without requiring them to actively think about their use.

Other strategies for saving energy mentioned by focus group participants who had a kitchen stove (without induction) were to turn down the stove slightly before the food is ready to make use of the excess heat from the hot plate and to boil water in a kettle instead of on the stove because the kettle, in that case, is perceived as being more efficient. Turning off the lights when leaving the room is another practice that some households reported engaging in. However, one household explained that due to the layout of the apartment, insufficient daylight entered through the windows, and therefore, they compensated for the deficiency by often leaving the lights on, even when nobody was in the room.

One of the interviewees living in a rental apartment suspected that the appliances included in the apartment were of a rather low standard and not very energy efficient. An example of an appliance feature intended to improve energy efficiency but that actually contributed to wasteful behavior was mentioned by another interviewee: Her new fridge had a door that was very difficult to open if you had already opened it shortly before. To avoid the inconvenience of not being able to open the fridge on consecutive occasions, it was sometimes left open for a while.

\subsubsection{Food}

Many participants expressed that avoiding food waste was a high priority for them. However, this seemed to be a complex task that is sometimes difficult to fulfill. In discussions, food waste, especially that of vegetables and fruits that spoil before being used, was an issue addressed by several interviewees. Several factors seem to contribute to this problem. One interviewee explained the problem of spoilage:

"I want the children to eat a lot of fruit, but sometimes it goes bad. Or, speaking of time, I go to the store, I buy a lot of vegetables, but I don't have time to cook them and they go bad. It's a concern indeed. I can open the fridge and see: 'I bought that, my God, I have to cook that sometime', (or) 'Oh, the mushrooms are still there', you know?" (I-8)

Another interviewee who related the same problem explained that one reason for food waste was a lack of space in the fridge, with the result being that vegetables are stored too tightly, which creates a moist and unfavorable environment where the vegetables do not stay fresh for long. This resulted in " ... one of those eternal problems, to go grocery shopping all the time" (I-1). Several other households had adopted the strategy of going shopping for smaller amounts of food more often. A third household that shared this issue explained how the fast decay of vegetables can occur as a consequence of the temperature in the fridge being too low. As will be further described in Section 4.2.2., this household solved the problem by including an extra fridge set at a higher temperature when renovating their kitchen (I-3). Two of the focus group participants had, in previous dwellings, a pantry placed against a wall facing the north with a valve to let in fresh, cool air, and this maintained a low temperature suitable for root crops, vegetables, and fruit. Both of them missed this feature in their current kitchens, and one of them said that "it's like an old-fashioned pantry, but if I were to build myself a new kitchen, I would definitely have it" (F-1). A different idea concerning both energy savings and the avoidance of food waste was suggested by one of the interviewees. To be able to easily get an overview of what is inside 
the fridge without opening it, he suggested that a transparent fridge door could be combined with a lamp button on the outside (I-19). However, not only refrigerated foods end up as waste. Regarding groceries stored in cabinets, one interviewee explained that "You don't see what you have at home so you buy a lot of food you already have. I think that is not very sustainable. In the end, you have four packages of the same thing at home just because they always end up at the back" (I-5).

Despite efforts to minimize food waste, some food waste cannot be avoided. A common practice among the participating households was to sort their food waste for either collection for biogas production or placement at a private compost site. The second alternative was only adopted by two households living in villas, but several other households expressed an interest in having either a private compost site or one that is shared by the HA. One household had bought an indoor compost solution called Bokashi and explained its operation:

"It somehow gets fermented. I don't know, but you chop down the vegetables a little, and then it goes much faster until it becomes soil. Cause in my dream I had all this nutrition that just goes to biogas. And then, we are growing plants ourselves ( ... All this fine nutrition ( ... ), organic fruits and vegetables that just go somewhere else. It's really weird actually." (I-2)

Interest in this compost solution was also expressed by another interviewee as well as in the focus group. One focus group participant pointed out that "I think it would feel very good, I think I would feel happy with myself, if I did it right" (F-4), and another opined, "But also, when you live in an apartment, to be able to do such things, you think that belongs to houses, but everyone can do that" (F-6). Another solution for taking care of food waste that was desired by a few participants was a food waste grinder. However, because such a machine is prohibited in their municipality, none of them had adopted one in their kitchens.

In discussions about kitchen designs supporting sustainably oriented cooking, one interviewee mentioned that vegetarian cooking demands more workspace because "it's a lot of chopping" (I-3).

\subsubsection{Packaging Waste}

"We have such a packaging society that is so sick" (I-19). This was the opinion of one of several households who expressed exasperation with the tedious process of managing the large quantities of packaging that enter the home together with purchased groceries. One household used a home delivery service for groceries and typically received approximately six bags of groceries in each delivery. They would have liked to be able to return the bags to the delivery company so that they could be reused, but this service was currently not available (I-12). Furthermore, three interviewees discussed the possibility of moving towards packaging-free grocery shopping. One interviewee stated that she would have liked to have "a system in the kitchen where you bring your own boxes to the store and fill them up with what you need" (I-5).

A general opinion among both focus group participants and interviewees residing in all types of dwellings was that the space dedicated to waste sorting in the kitchen is insufficient. One household opined, "Many times the reason to why we are very poor at recycling is because we don't have a natural place to put it. After all, we have filled up what we have there", and "Since recycling has grown faster over time than the sink (cabinet), I think we should go up one module (size) soon as the standard" (I-3). Two interviewees also discussed how the current system of sorting all the different waste categories is too demanding for households:

"I feel that it's important with these systems, because I think that helps people to be ( ... ) that the most natural, easy choice is the most environmentally friendly ( . . . I don't like when you put too much (responsibility) on the individual, (implying) that it is the individual's fault, (that) they are the ones that don't recycle-it's the producers who don't take their responsibility." (I-2) 


\subsection{Kitchen Renewal}

Of the six interviewed condominium-residing households, three had completed an extensive kitchen renovation that included renewal or touch up of kitchen furniture, appliances, flooring, and wall coverings. Of the other three households, two had recently moved in and were not planning to renovate their kitchens in the near future. The third household was in the process of planning a kitchen renovation and had earlier replaced a few appliances.

Of the seven households living either in a villa or terraced house, all had performed an extensive renovation according to the previously stated criteria. For rental apartments, extensive renovations had been completed in three out of seven cases. An overview of the finished changes in the interviewed households is given in Table 4 .

\subsubsection{Motivations for Kitchen Renovations and Desired Changes}

For several of the interviewed households, renovation was seen as a necessity for being able to enjoy using the kitchen. Some of them disliked the layout of the previous kitchen, experienced a lack of workspace, or thought that the kitchen was generally too small. The estimated age of the kitchens before renovation varied greatly. When the previous kitchen was perceived to be worn out or outdated, either functionally or aesthetically, this was often the main motivation for undertaking the renovation. One interviewee living in a rental apartment explained their request for a renovation:

"About three months ago, I called (the landlord) and said that our kitchen is falling apart ( ... ) Now I want you to completely renovate the kitchen because this doesn't feel okay anymore ( ... ) It had cracked all over." (I-5)

Another household had lived in the same rental apartment for 23 years without any kitchen renovation being made. The interviewee described the kitchen as being very small relative to the total size of the apartment and also very old. Compared with 'normal' kitchens today, she thought that "most things are missing. I have a very old stove and no dishwasher, this (compact dishwasher) I bought myself. Such everyday tools are missing" (I-18). She, as well as another tenant interviewee, expressed a wish for both a dishwasher and microwave oven to be included as standard equipment in rental apartments (I-16 and I-18). Interviewee I-18 also thought that in an apartment that is big enough for an entire family, it should be standard to have separate, full-size fridges and freezers. One interviewee living in a condominium explained that one of the main reasons for undertaking their renovation of the kitchen was that "the lack of a dishwasher was (an) important (problem) to solve" (I-4).

Another motivation to functionally update the kitchen given in two interviews was that old kitchens tend to have shelves behind cabinet doors that are cumbersome to reach into when attempting to get an overview of the content. This is easier with drawers (I-12 and I-14). Among the households living in rental apartments, it was commonly desired to have more storage and workspace. Two interviewees specifically mentioned that they would want a kitchen island (I-16 and I-17), and three would want better waste sorting facilities (I-5, I-17, and I-19). Other desired changes were to have materials of higher quality in the kitchen (I-5 and I-17), a kitchen that is more minimalistic and easy to clean (I-5), built-in appliances (I-5), updated wallpaper or paint (I-15 and I-16), and more light (I-17). A couple living in a condominium who had not yet renovated the kitchen but planned to do so experienced a lack of light in their current kitchen and saw this as their main motivation to undertake a kitchen renovation (I-12). Overall, enhancing the appearance of the kitchen was a common reason for kitchen renovations. One interviewee living in a condominium mentioned that renovating the kitchen was a good investment for maintaining the apartment in a good condition (I-1). 
Table 4. Overview of renovations made in the residences of interviewed households. For demographic details of the households, see Table 3.

\begin{tabular}{|c|c|c|c|c|c|c|c|c|c|c|c|c|c|c|}
\hline Ü & 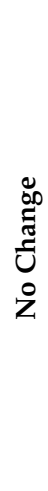 & 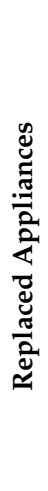 & 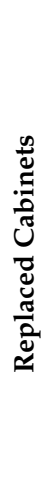 & 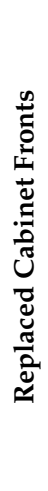 & 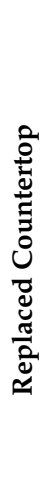 & 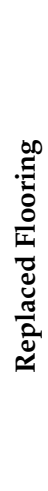 & 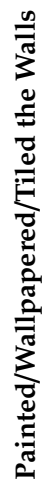 & 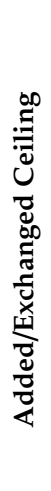 & 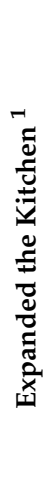 & 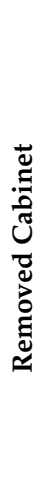 & 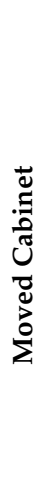 & 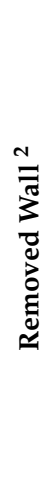 & 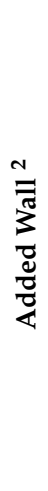 & 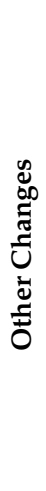 \\
\hline I-1 & & $x$ & $x$ & $X$ & $X$ & $X$ & $x$ & & $x$ & $x$ & $x$ & & & \\
\hline I-2 & & $x$ & & & $x$ & $X$ & $X$ & & & $X$ & & & & $x$ \\
\hline I-3 & & $X$ & $X$ & $X$ & $X$ & $X$ & $X$ & $X$ & $X$ & & & $X$ & & \\
\hline $\mathrm{I}-4$ & & $X$ & $X$ & $X$ & $X$ & $X$ & $X$ & & $X$ & $X$ & & & & \\
\hline I-5 & & $X$ & & $X$ & & & $X$ & & & $x$ & & & & $x$ \\
\hline I-6 & $X$ & & & & & & & & & & & & & \\
\hline $\mathrm{I}-7$ & & $X$ & $X$ & $X$ & $X$ & $X$ & $X$ & & $X$ & $X$ & $X$ & $X$ & & $X$ \\
\hline I-8 & & $X$ & $X$ & $X$ & $X$ & $X$ & $X$ & & $X$ & $x$ & $x$ & & & \\
\hline I-9 & & $X$ & $X$ & $X$ & $X$ & $X$ & $X$ & $X$ & $X$ & $X$ & $X$ & $X$ & $X$ & \\
\hline $\mathrm{I}-10$ & & $X$ & $X$ & $X$ & $X$ & $X$ & $X$ & $X$ & $X$ & $X$ & $X$ & $X$ & & \\
\hline I-11 & $X$ & & & & & & & & & & & & & $X$ \\
\hline I-12 & & $X$ & & & & & & & & & & & & \\
\hline I-13 & & $X$ & $X$ & $X$ & $X$ & $X$ & $x$ & $X$ & $X$ & $X$ & & & & \\
\hline I-14 & & $X$ & $X$ & $X$ & $X$ & $X$ & $X$ & $X$ & $X$ & $X$ & $X$ & $X$ & & \\
\hline I-15 & $X$ & & & & & & & & & & & & & \\
\hline I-16 & $X$ & & & & & & & & & & & & & \\
\hline I-17 & $X$ & & & & & & & & & & & & & \\
\hline I-18 & $X$ & & & & & & & & & & & & & \\
\hline I-19 & & $X$ & & $X$ & $X$ & $X$ & $X$ & & & & & & & \\
\hline $\mathrm{I}-20$ & & $X$ & $X$ & $X$ & $X$ & & $X$ & & $X$ & & & & & \\
\hline
\end{tabular}

Interestingly, one interviewee explained that it might seem more acceptable to live with an older kitchen if a renovation is a future possibility. Hence, the kitchen's lifetime can get prolonged slightly (I-2). Another interviewee described how she had postponed the kitchen renovation for several years but finally felt that it could not be delayed any more:

"It (the kitchen renovation) was necessary so I could thrive in the kitchen. I thought about it for several years, and at last, I had to deal with it. It demands energy, money, stamina and so on, but finally, I forced myself. It was actually resistance, I would say, at the same time, I knew that I needed to do something about it. It wasn't a practical kitchen in my opinion." (I-8)

One family living in a terraced house explained that the kitchen renovation partly followed as a consequence of other renovations of their home. Because they needed to replace the floor joists, they took the opportunity to completely transform the kitchen at the same time. The main motivation for this, they explained, was that their needs in the kitchen changed completely when they had children, even though the couple had different opinions regarding the functionality of the previous kitchen.

"The main reason for us to step away from this U-kitchen, more than that $\mathrm{X}$ always wanted to do something modern with it, but the reason why I gave my approval, in the end, was that when you have a family, you have completely different needs in the kitchen. I thought it was so exciting how the needs shifted because, suddenly, you are standing in the kitchen 
where you do a lot of things and there are pacifiers to be boiled and gruel bottles, and then you can't see what happens on the other side of the corner. Because you actually need to see what's going on, where these two are going or when they are swallowing Legos or whatever it may concern." (I-3)

\subsubsection{Renovation Strategies and Environmental Consequences}

The extent to which the different households renovated their kitchens varied greatly, as shown in Table 4. One of the households that made a complete renovation had thought about mainly exchanging the cabinet fronts and keeping most other parts of the kitchen. However, because she disliked the layout of the old kitchen, she was concerned that she still would not feel completely satisfied after the renovation. Therefore, she decided that "now it may cost a little more, but maybe I will be more satisfied and it will feel practical, and I will get what I want anyway" (I-8).

One interviewee explained that they wanted to make a more sustainably oriented renovation of the kitchen. Therefore, instead of replacing the entire kitchen, they decided to repaint it but keep the existing cabinets and cabinet fronts and replace only some of the old appliances, the countertops, sink and faucet, flooring, handles, lighting, and power outlets. The interviewee explained that, in the end, the result exceeded her expectations. However, she also explained that two contributing reasons for why they decided to not make a full renovation were, first, that the existing kitchen was in relatively good shape and, second, they expected to stay in that house for a maximum of 5-10 years more. If they had planned to live in that house for longer, they might have considered making a full renovation instead (I-2).

Another household was planning to buy second-hand cabinet frames and had searched for those on an online marketplace, but finally, they decided to buy a new kitchen branded as a low-impact kitchen with frames made of biocomposite. However, they bought one second-hand upper cabinet and some second-hand appliances, which they included in their new kitchen. Additionally, they bought some appliances that had either been produced in Sweden or even locally in the same town (I-7).

Of the three kitchen renovations performed in rental apartments, one was completed by the household itself and two were mainly overseen by the landlords. In the first case (I-20), the household was offered a kitchen that was barely used from another household, simply because the former owner wanted to install a wine cooler that was $20 \mathrm{~mm}$ too deep. Instead of exchanging only the countertop to make it fit, she decided to buy a new kitchen. In the other two cases, the landlord either replaced the cabinet fronts and appliances (I-19) or repainted the cabinet fronts and replaced only those that were broken, while appliances were exchanged in several rounds as they broke down (I-5). In both cases, no changes were made to the overall layout of the kitchen.

One of the households that completely transformed its kitchen explained that in selecting specific products and materials for their new kitchen, they aimed to select timeless designs with the motivation to both optimize the ability to sell their home in the future and create good conditions for sustainability over time. They chose smooth white cabinet fronts because these would make it easy to complement the kitchen in the future. For the countertop, they chose oak rather than stone because a wooden board is "sandable and you can oil it, so even though it is sensitive, it can live many lives", whereas a stone countertop can crack and "then it is broken forever" (I-3).

However, preferences varied greatly. Materials and designs were selected on the basis of specific needs, style preferences, quality, budget, ease of cleaning, convenience, environmental considerations, and the product range available on the market. Four of the interviewed households who had renovated their kitchens explained that in the planning of their new kitchens, they aimed for a design that would be in line with the style and time period of the building (I-3, I-4, I-9, and I-14). Three households specifically selected kitchens made of solid wood (I-4, I-9, and I-10).

Of the households that renovated their kitchens, all exchanged at least some of their appliances. In many cases, the existing appliances were either broken, dysfunctional, or outdated. Regarding the fridge and freezer, it was mentioned that new models consume considerably less energy than the old 
appliances that were replaced. In other cases, the existing appliances simply did not fit in the new kitchen, either in style or dimension. As one interviewee explained, "I did not want to place them in my new kitchen" (I-3). Only two households retained some appliances from their old kitchen in their new kitchen (I-2 and I-14). However, both of them had already replaced some broken appliances before they commenced the main renovation of their kitchens. One of them explained how they were forced to adapt their existing kitchen to be able to accommodate a new fridge because they could not find a fridge of the same height as their last one (I-2). The interviewee from the second household explained that "at some point, we decided to buy stainless steel so that it probably fits however we choose to do the kitchen later" (I-14). Two households kept their old fridges for use as an extra beer or wine fridge in the basement or garage (I-1 and I-10).

Because of the likeliness of having to replace appliances before replacing kitchen furniture, one household avoided installing built-in appliances in their kitchen. The interviewee pointed out that "it's probably the appliances that will break, the rest will last longer. The fronts, okay, but they are still of decent quality and can probably be repainted at some point before the kitchen needs to be replaced" (I-14).

In the selection of new appliances, some households prioritized energy efficiency. One interviewee explained that he had the intention of finding a solution for reusing thermal energy from the hood but did not manage to do so (I-13). Another household specifically wanted a hood that they could control from their smartphones via Bluetooth because they lacked sufficient ventilation in their home. Moreover, they selected an oven with a pyrolysis function that would reduce the need to clean the oven (I-14). Induction hobs were generally very popular, and several interviewees described them as efficient. However, one interviewee complained about their new induction hob emitting a high-frequency sound that she could hear even from the opposite end of the house. She explained that she appreciated the efficiency of induction, "but if it is at the expense of hurting your ears every time you cook, we are not in such a hurry, then you can afford five minutes more for it to be more enjoyable" (I-2).

A common activity connected to the renovation of kitchens seemed to be getting rid of small appliances and other products in the kitchen that were no longer needed (I-1, I-2, I-4, I-7, I-13, and I-14). Four households explained that when they bought an induction hob, this reduced the need for a kettle (I-2, I-4, I-7, and I-13). One household specifically selected a steam oven so that they would be able to heat up the food almost as quickly as in a microwave oven and thereby get rid of that particular appliance (I-7).

In addition to replacing existing appliances, three households added a dishwasher to their kitchens (I-4, I-7, and I-14), and one household added a wine cooler (I-4). One household explained how they experienced a problem with their old kitchen with respect to the storage of vegetables since they spoiled quickly when stored in a regular fridge. Therefore, when renovating the kitchen, they added an extra fridge, which they set on the highest temperature level. In this way, the extra fridge now functions as a cooler specifically for vegetables:

"It's actually a huge difference. I'm thinking about before we got the cooler, it was so difficult to store vegetables in the fridge, and they got so bad and we threw away so much. So, in the end, we didn't buy that much green stuff because they turned bad in that climate." (I-3)

A similar but simpler solution was used by another household. This household adopted a function from their old kitchen that entailed placing a tall cabinet next to the outer wall with an air valve that naturally keeps the space cool during wintertime, if the valve is open (I-4). Another household had plans to include the same solution when they renovated their kitchen. However, due to a lack of space, they instead prioritized getting more workspace. Nevertheless, they expressed plans to eventually integrate a cabinet that is naturally cooled from the outside in another space next to the kitchen (I-7).

Replaced appliances were either sold, given away, or taken to a recycling center. Only two households sold their old kitchen furniture (I-3 and I-9), whereas the others left theirs at a recycling station or in a garbage room. 


\subsubsection{Kitchens After Renovation}

None of the households that had renovated their kitchens had any intention of renovating their kitchens again while living in the same house or apartment. All of them reported that they were satisfied with the result, with the exception of some minor details in a few cases as well as an increase in rent incurred by one household where the landlord had performed the renovation (I-19). For one household, a consequence of the renovation was that they were now more careful in using their new kitchen (I-3). An unintended consequence experienced by another household was that the new waste sorting space turned out to be insufficient (I-10).

\subsection{Barriers to Kitchen Circularity}

Several interviewees and focus group participants expressed frustration regarding the poor quality of both kitchen furniture and appliances. Problems such as sensitivity to water, paint that easily wears off, surfaces that are prone to wear, stain, or shift color, and difficulties in cleaning were some examples of issues that contribute to kitchen furniture not aging well. One interviewee discussed durability:

"I think it's very worrisome that kitchens today have rather limited durability because they are veneered and really quite fragile units. One of our first kitchens was solid wood, and also, the (apartment) we moved from ( ... ) That kitchen was 70 years old, and it had been repainted a number of times and was so fine. I told the broker that we would sell it to anyone, but on the condition that they would not tear out the kitchen because there are very few who have the sense, understanding, and budget to put in a kitchen that is of equally high quality." (I-11)

A few households were disappointed in new appliances that broke down very shortly after they were installed. One household had replaced their dishwasher twice in a period of only four months because the first two had released so much steam that the wooden countertop above was damaged (I-3). A household living in a rental apartment had their stove replaced twice in a period of six years (I-5). Two other households felt disappointment about a dishwasher breaking after five years (I-13) and a fridge after three years (I-2).

In addition to poor quality and the difficulty in repairing kitchen appliances and furniture, it was also discussed how many kitchens get replaced because functional aspects do not meet the current needs of the household, as presented earlier. However, it was clear that a significant share of kitchen renovations was performed mainly due to aesthetic reasons. Many participants reflected on the strong influence of trends in kitchen design and the status connected to renovating the kitchen, opining, "We have so much higher demands on interior design, it should be exactly the way I want it so that it matches my lifestyle and identity ( . . ) but the difficulty is that the interior is so trend-sensitive" (I-7) and "I think we are so extremely influenced by what other people do ( . . . ) It's very difficult to stand strong when everyone else is replacing their kitchens" (I-2). It was also discussed how it is not enough expensive or difficult to tear out the entire kitchen and buy a new one: "As long as people have money and there are fairly cheap kitchens to buy, then they will replace it just because it is not the same white color as desired" (I-20). One interviewee expressed skepticism towards sustainability marketing: "I see a danger in that the kitchen industry and home, our home goes more and more towards this 'wear and tear consumption' and that these sustainability labels have become more and more a label to relive our bad conscience rather than actually achieve any effect" (I-5).

\section{Discussion}

In the following sections, on the basis of the findings, design strategies for promoting circular consumption with respect to kitchen furniture and appliances as well as the daily use of kitchens are discussed. 


\subsection{Design Strategies for Enabling Circular Consumption of Kitchens}

To determine how to overcome the existing barriers to extending the circular economy to kitchens, we reviewed the study participants' opinions regarding a range of different approaches to extending the lifespan of kitchens. Some participants focused on improving quality and timeless design: "It's important to do something that is so good and so timeless that you understand that this is a treasure, it's an inheritance (... ) But that requires a completely different authenticity in materials and that it can withstand both wear from the eye and the hand" (I-11). Others focused on emotional values: "In my experience, it's often forgotten to do something that has an emotional value somehow. If we do something and we strive for it to be beautiful, functional, of good material and such, then I think there's a desire to care for it in a different way ( ... ) So I think we should try to get people to appreciate how things can age and how they can do it in a beautiful way" (I-4). This connects to several design strategies that focus on long life and use of products, for instance, design for physical and emotional durability [20], and design for attachment and trust, as well as design for reliability and durability [19].

In connection with discussions regarding quality and longevity, it was also discussed to what extent kitchens should be personalized in order to fulfill needs and preferences over time: "The way we build condominiums today, when you have some general kitchen that everyone is supposed to like, everyone gets white kitchens with that countertop and those 1990s handles. Maybe that's not the right way to build new homes, maybe you should select yourself which kitchen you want when you move in. But it's difficult, then you might choose something green and very striking" (I-5). To enable an aesthetic upgrade of the kitchen without making a complete renovation, some participants liked the idea of having a durable, high-quality frame that lasts many years with fronts that can easily be replaced or repainted: "If you have the frames in good quality, then it's relatively easy to perform a face-lift on a kitchen" (I-13).

However, as frequently mentioned in the interviews, kitchen needs can change completely due to lifestyle changes such as starting a family or children growing up and moving out. If the kitchen is to be functionally upgraded through moving units or changing cabinet interiors, this places even higher demands on modularity in design. For this reason, some participants thought that there should be an even higher level of standardization and collaboration between different kitchen producers.

To address the varying needs and preferences regarding aesthetics and functionality identified previously, the examples of relevant design strategies included here are those that focus on extending the life and use of products, for instance, design for maintenance and upgrading [20], and design for ease of maintenance and repair, upgradability and adaptability, standardization, and compatibility, and dis- and reassembly [19]. Furthermore, to address the problem of appliances and furniture that break, design strategies are needed both for extending life and use, as described above, as well as for reversing obsolescence, which den Hollander et al. divide into design for recontextualizing, repair, refurbishment, and remanufacture [20].

Regarding appliances, opinions were split as to whether, from a circularity perspective, it would be better to have them built in or free standing. One interviewee argued that free-standing appliances make it easier to "exchange units without causing major 'secondary diseases'" (I-11), whereas another argued that "if it is integrated into the kitchen structure, I don't think you perceive it as being that old because it isn't visible" (I-5). Although, the second comment was mainly focused on preventing the aesthetic obsolescence of kitchen appliances, not functional obsolescence. However, as the findings have shown, functional obsolescence of kitchen appliances was commonly experienced by the participants. Therefore, such a strategy of 'hiding' the appliances would also have to be supported by the design strategies described above, especially design for dis- and reassembly.

Although the design of kitchen furniture and appliances has a major role to play in enabling circular consumption, it is also clear that changes on a systemic level are needed to support a circular economy of kitchens. One interviewee opined, "a more secure secondary market for products in the kitchen would have been good ( . . ) since it's not super expensive anyway, with a dishwasher, for instance, I would probably rather buy a new one and many other (people) for sure too. But if 
there were more secure suppliers of used products, that maybe you could get some guarantees $(\ldots)$ then I could imagine buying more second-hand there" (I-17). It is evident that new business models for kitchens are needed. However, this study focused mainly on design aspects for enabling circular consumption of kitchens and thus we cannot provide recommendations regarding specific circular business models suitable for the kitchen industry. Therefore, further research is needed to investigate opportunities for new services relating to the kitchen as well as relevant business collaborations, ownership models, etc. Because the kitchen connects to a wide range of stakeholders and is subject to many different resource flows, it is highly relevant to apply a systems perspective to enable the transition to a circular economy of kitchens. For this reason, we believe the proposed strategy of Moreno et al., design for systems change [18], will have an important role to play.

Furthermore, some interviewees highlighted the interaction between product quality and people's attitudes: "You develop something that should be replaced quickly and people think it's trendy to replace it and keep up with the latest kitchen trend, so I think it's a big societal issue that needs to be discussed" (I-8). One interviewee compared the increased awareness regarding flight-related climate impacts to the need for higher awareness concerning the impact of kitchen replacements: "There should be more climate anxiety and shame connected to replacing a 10-year-old kitchen than traveling by air because I'm convinced that the kitchen has a much greater impact on climate than your air travel" (I-4). The question of how to increase awareness regarding the environmental impact of kitchens is also a topic that demands further research.

From the findings, it was noticed that thoughts regarding kitchen circularity did not differ much depending on what type of dwelling the participating households lived in. However, what did differ was the extent to which a household was able to make changes to its dwelling, with a higher level of opportunity to make changes evident among those who owned their kitchens, namely households living in condominiums, villas, or terraced houses. Such households could adapt their kitchens according to their needs, whereas households living in rental apartments were much more limited in what they could change, and therefore, often had to adapt themselves to the configuration of their existing kitchens instead.

\subsection{Design Strategies for Enabling Circular Consumption in the Daily Use of Kitchens}

Regarding the possibility of achieving circular resource consumption in the everyday use of kitchens, this study has shown that the manner in which a kitchen is designed may either support or hinder resource-efficient practices. For instance, the findings indicated that kitchens are generally not adapted to an increased intake of vegetables, as highlighted both by comments regarding how insufficient or unsuitable storage spaces for vegetables lead to faster decay and a lack of adequate workspace impedes the preparation of vegetables during cooking. Other factors that were found to have a negative influence on resource efficiency were a feature that makes it more difficult to open a fridge shortly after it has been closed, resulting in avoidance to close it, insufficient waste sorting space, leading to some categories of trash not being sorted, and a lack of a dishwasher, resulting in the more resource-intensive activity of washing the dishes by hand. Generally, the households were unaware of how much energy was consumed by the various appliances in their kitchens and were not encouraged to adjust their energy use.

However, some qualities appeared to contribute to reduced consumption. One interesting technique mentioned by several participants was to implement a cooler in the kitchen, either as a low-tech, naturally ventilated pantry or as a fridge set on the highest temperature. The environmental benefits of this solution seem to be twofold: Vegetables can be kept fresh for longer, thus preventing food waste, and less energy can possibly be used in this manner than by using a normal fridge. However, a limitation of the naturally cooled pantry solution is, of course, that it is only relevant in relatively cool climate regions. 
Several interviewees discussed no longer needing a kettle because they had obtained an induction hob. Thus, they were able to reduce the number of appliances in the kitchen. Another aspect that was found to be generally important in the design of kitchens for enabling sustainable resource use was the availability of enough space. This concerns adequate storage space for food and waste sorting as well as sufficient workspace to support various cooking techniques.

Generally, it seems that resource flows in the kitchen are not visible or apparent enough and that the households may not know how to perform their actions in a less resource-intensive manner. From a social practice theory perspective, it could be argued that competences or skills to act in a resource-efficient manner with respect to the various practices undertaken in everyday kitchen use are not sufficient. The materials or stuff used in the kitchen do not seem to provide the households with the skills needed to minimize resource use. Common images or meanings connected to resource use in kitchens seem to be that 'you should not throw away food' and 'you should sort your waste'. However, images of that you should minimize your energy use in the kitchen seem to be much weaker.

Based on the findings in this paper, we argue that kitchen design should focus on making resource use more visible. This does not mean making the storage of packaging waste and food waste more exposed. Rather, it should focus on the prevention of resource waste by, for instance, providing well-structured storage spaces to prevent groceries about to expire being hidden behind more fresh groceries, or making it clear which activities that contribute to unnecessarily high levels of water and energy use in the kitchen. In addition to better communication of resource use, the most efficient manner with which to use an appliance must be readily apparent to users. However, because this study has taken a holistic view on kitchen resource consumption, it cannot provide detailed descriptions regarding specific design solutions to promote behavioral change. This remains a topic for further research.

\section{Conclusions}

This paper has presented insights into kitchen-related resource use in households of varying compositions, ages, and dwelling types. Resource use has been explored from a wide perspective with respect to both daily kitchen use and transformations of the kitchen with the aim of identifying design strategies to enable circular consumption of kitchens and the resource flows connected to their use. As the findings have shown, kitchen design plays an important role in supporting efficient resource use within the kitchen. Providing a well-planned layout and an appropriate amount of storage spaces may both prevent food waste and support a high level of recycling of packaging waste. Regarding the storage of vegetables, there was interest in a return to the naturally cooled pantry as a low-energy solution to keep vegetables fresh for longer. Providing enough workspace is important to support cooking, especially when preparing vegetables, which is an important aspect of vegetarian cooking. Furthermore, kitchens should be equipped with features that can help households to use energy and water efficiently, for instance, a dishwasher. With a set of well-functioning main appliances, households might have a need for fewer appliances: An induction hob may, for instance, reduce the need for a kettle, which may save both storage space and production-related resource consumption. It was also apparent that kitchens and kitchen appliances generally do not guide users to minimize their resource use. Further research is therefore needed to investigate how resource flows in the kitchen could become more visible and how the products in the kitchen could provide households with the necessary skills to minimize their resource use.

This article has presented various motivations that may initiate a kitchen renovation:

1. functional demands and changing needs,

2. aesthetic demands and changing trends,

3. obsolescence due to wear,

4. linkage to another home renovation. 
In some cases, sustainability considerations were found to motivate specific choices, such as choosing a lower degree of renovation or selecting energy-efficient, locally produced, or second-hand appliances. However, sustainability considerations were not found to be the main motivation behind any renovation.

Because kitchens are such a central part of our homes, they should also be a place where we thrive. From the findings in this article, we can conclude that kitchens are generally not flexible and adaptable enough to meet the various needs connected to both lifestyle changes of members of the same household and new demands when the dwelling is either sold to or rented to a new household. Due to the lack of possibilities to upgrade the kitchen either functionally or aesthetically with small changes, many households participating in this study completely renovated their kitchens and replaced (almost) everything.

To attain a higher level of kitchen circularity and take into account the various needs and desires of households, a combination of design strategies is needed. Circular design strategies suggested in previous studies were found to be highly relevant also in the case of the kitchen, including design for systems change, as identified by Moreno et al. [18], design strategies for resisting, postponing and reversing obsolescence, as proposed by den Hollander et al. [20], and design strategies to slow and close resource loops, as proposed by Bocken et al. [19]. The different frameworks, of course, share similarities, but they approach the issue from different perspectives, which were all found to be useful. However, these design strategies also need to be accompanied by circular business models that are relevant to the kitchen industry as well as striving to increase public awareness of the environmental impact connected to the kitchen. This also remains a topic for further research.

Author Contributions: S.H. planned the study together with A.O., with input from P.F. and U.R. S.H. and A.O. performed the data collection and analyzed the data together. S.H. lead the work of writing the paper with contributions from A.O. P.F. and U.R. reviewed and edited the paper. All authors have read and agreed to the published version of the manuscript.

Funding: This research was funded by EIT Climate-KIC, EIT reference KAVA number Circular Kitchen 2.4.6.

Acknowledgments: We would like to direct a special thanks to Giliam Dokter, who is a member of the research team of the CIK project and took part in the planning and execution of the focus group session. Many thanks also to all research participants for your time and valuable inputs.

Conflicts of Interest: The authors declare no conflict of interest.

\section{References}

1. Hand, M.; Shove, E.; Southerton, D. Home Extensions in the United Kingdom: Space, Time, and Practice. Environ. Plan. D Soc. Sp. 2007, 25, 668-681. [CrossRef]

2. Maller, C.; Horne, R.; Dalton, T. Green Renovations: Intersections of Daily Routines, Housing Aspirations and Narratives of Environmental Sustainability. Hous. Theory Soc. 2012, 29, 255-275. [CrossRef]

3. Hoxha, E.; Jusselme, T. On the Necessity of Improving the Environmental Impacts of Furniture and Appliances in Net-Zero Energy Buildings. Sci. Total Environ. 2017, 596-597, 405-416. [CrossRef] [PubMed]

4. Femenías, P.; Holmström, C.; Jonsdotter, L.; Thuvander, L. Arkitektur, Materialflöden Och Klimatpåverkan $i$ Bostäder; Chalmers University of Technology: Gothenburg, Sweden, 2016.

5. European Environmental Bureau. Circular Economy Opportunities in the Furniture Sector; European Environmental Bureau: Brussels, Belgium, 2017.

6. European Remanufacturing Network. Remanufacturing Market Study; European Remanufacturing Network: Aylesbury, UK, 2015.

7. Wang, F.; Huisman, J.; Stevels, A.; Baldé, C.P. Enhancing E-Waste Estimates: Improving Data Quality by Multivariate Input-Output Analysis. Waste Manag. 2013, 33, 2397-2407. [CrossRef]

8. CECED. Material Flows of the Home Appliance Industry; European Committee of Domestic Equipment Manufacturers: Brussels, Belgium, 2018. [CrossRef]

9. Ghisellini, P.; Cialani, C.; Ulgiati, S. A Review on Circular Economy: The Expected Transition to a Balanced Interplay of Environmental and Economic Systems. J. Clean. Prod. 2016, 114, 11-32. [CrossRef] 
10. European Environment Agency. Circular by Design: Products in the Circular Economy; European Environment Agency: Copenhagen, Denmark, 2017. [CrossRef]

11. Ellen MacArthur Foundation. Towards a Circular Economy: Business Rationale for an Accelerated Transition; Ellen MacArthur Foundation: Cowes, UK, 2015.

12. Bakker, C.; Wang, F.; Huisman, J.; Den Hollander, M. Products That Go Round: Exploring Product Life Extension through Design. J. Clean. Prod. 2014, 69, 10-16. [CrossRef]

13. Wastling, T.; Charnley, F.; Moreno, M. Design for Circular Behaviour: Considering Users in a Circular Economy. Sustainability 2018, 10, 1743. [CrossRef]

14. Selvefors, A.; Rexfelt, O.; Renström, S.; Strömberg, H. Use to Use - A User Perspective on Product Circularity. J. Clean. Prod. 2019, 223, 1014-1028. [CrossRef]

15. Elias, E.W.A.; Dekoninck, E.A.; Culley, S.J. Designing for 'Use Phase' Energy Losses of Domestic Products. Proc. Inst. Mech. Eng. Part B J. Eng. Manuf. 2009, 223, 115-120. [CrossRef]

16. Hager, T.J.; Morawicki, R. Energy Consumption during Cooking in the Residential Sector of Developed Nations: A Review. Food Policy 2013, 40, 54-63. [CrossRef]

17. Hobman, E.V.; Stenner, K.; Frederiks, E.R. Exploring Everyday Energy Usage Practices in Australian Households: A Qualitative Analysis. Energies 2017, 10, 1332. [CrossRef]

18. Moreno, M.; De los Rios, C.; Rowe, Z.; Charnley, F. A Conceptual Framework for Circular Design. Sustainability 2016, 8, 937. [CrossRef]

19. Bocken, N.M.P.; de Pauw, I.; Bakker, C.; van der Grinten, B. Product Design and Business Model Strategies for a Circular Economy. J. Ind. Prod. Eng. 2016, 33, 308-320. [CrossRef]

20. Den Hollander, M.C.; Bakker, C.A.; Hultink, E.J. Product Design in a Circular Economy: Development of a Typology of Key Concepts and Terms. J. Ind. Ecol. 2017, 21, 517-525. [CrossRef]

21. Gram-Hanssen, K. Understanding Change and Continuity in Residential Energy Consumption. J. Consum. Cult. 2011, 11, 61-78. [CrossRef]

22. Nicholls, L.; Strengers, Y. Peak Demand and the 'Family Peak' Period in Australia: Understanding Practice (in)Flexibility in Households with Children. Energy Res. Soc. Sci. 2015, 9, 116-124. [CrossRef]

23. Strengers, Y.; Nicholls, L.; Maller, C. Curious Energy Consumers: Humans and Nonhumans in Assemblages of Household Practice. J. Consum. Cult. 2016, 16, 761-780. [CrossRef]

24. Martens, L.; Scott, S. Understanding Everyday Kitchen Life: Looking at Performance, into Performances and for Practices. In Methodological Reflections on Practice Oriented Theories; Jonas, M., Littig, B., Wroblewski, A., Eds.; Springer: Cham, Switzerland, 2017; pp. 177-191. [CrossRef]

25. Shove, E.; Watson, M.; Hand, M.; Ingram, J. The Design of Everyday Life; Berg: New York, NY, USA, 2007.

26. Hand, M.; Shove, E. Condensing Practices: Ways of Living with a Freezer. J. Consum. Cult. 2007, 7, 79-104. [CrossRef]

27. Phillips, C.; Waitt, G. Keeping Cool: Practicing Domestic Refrigeration and Environmental Responsibility. Geogr. Res. 2018, 56, 68-79. [CrossRef]

28. Reckwitz, A. Toward a Theory of Social Practices. Eur. J. Soc. Theory 2002, 5, 243-263. [CrossRef]

29. Shove, E.; Pantzar, M.; Watson, M. The Dynamics of Social Practice: Everyday Life and How It Changes; SAGE Publications Ltd.: London, UK, 2012.

30. Kuijer, L. Implications of Social Practice Theory for Sustainable Design. Ph.D. Thesis, Delft University of Technology, Delft, The Netherlands, 7 February 2014.

31. Flick, U. Doing Focus Groups. In An Introduction to Qualitative Research; Owen, A., Ed.; SAGE Publications: Thousand Oaks, CA, USA, 2018; pp. 254-276.

32. Jenks, C.J. Recording and Transcribing Social Interaction. In The SAGE Handbook of Qualitative Data Collection; Flick, U., Ed.; SAGE Publications Ltd.: Thousand Oaks, CA, USA, 2018; pp. 118-130. [CrossRef]

33. Gioia, D.A.; Corley, K.G.; Hamilton, A.L. Seeking Qualitative Rigor in Inductive Research: Notes on the Gioia Methodology. Organ. Res. Methods 2013, 16, 15-31. [CrossRef]

(C) 2020 by the authors. Licensee MDPI, Basel, Switzerland. This article is an open access article distributed under the terms and conditions of the Creative Commons Attribution (CC BY) license (http://creativecommons.org/licenses/by/4.0/). 